\title{
The Relationship Between Market And Accounting Determined Risk Measures: Reviewing And Updating The Beaver, Kettler, Scholes (1970) Study
}

Michael Jarvela, Lakehead University, Canada

James Kozyra, Lakehead University, Canada

Carla Potter, Lakehead University, Canada

\begin{abstract}
The association between market-determined risk measures and accounting-determined risk measures was originally explored in the 1970s by Beaver, Kettler, and Scholes (BKS). The results of the BKS (1970) study suggest that accounting information is usefulness in assessing firm specific risk. Since BKS, there have been few studies conducted to determine if these results still hold today. This cross-sectional study re-examines the relationship between market and accounting-determined risk measures. A total of 222 randomly selected publicly traded companies were examined to determine if there is a relationship between the accounting risk measures of dividend payout ratio, leverage, and earnings variability and the market risk measure of beta. The relationship is further analyzed by classifying the results based on the company's size (market capitalization). Our study suggests that the original BKS (1970) results hold true in today's market with some exceptions. These findings reiterate the importance of accounting policy choice and full disclosure in the financial statements, as accounting information proves to be a possible alternative to market risk information. This demonstrates that full disclosure is important to help capital markets determine a company's risk profile.
\end{abstract}

Keywords: Market risk measures; accounting risk measures

\subsection{INTRODUCTION}

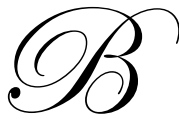

eta is one of the most common measure of risk among investors. Beta is a measure of the covariance of returns for a security compared with the covariance of returns for the market. Accountants, on the other hand, have many other determinants of risk including the level of firm leverage, earnings variability and an inverse relationship to dividend payout. This study examines the relationship between marketdetermined risk measures and accounting-determined risk measures using the methodology set out by Beaver, Kettler and Scholes (1970) (referred to as BKS (1970) from this point forward). Examining the relationship between market-based and accounting-based risk measures is important for many reasons. Firstly, if both market and accounting based risk measures are in agreement, investors will be able to rely on accounting determined risk measures as indicators of company-specific risk in the absence or instability of market risk measures. Secondly, many investors rely on accounting data as part of their fundamental analysis when determining risk and reward expectations. The purpose of this study is to determine if the BKS (1970) results still hold true in the current capital markets, and to further understand the role of accounting in the capital markets.

To test the relationship, 222 firms were examined. The sample was selected on the basis of market capitalization, with equal weighting given to firms with small, medium, and large market capitalization. An OLS regression estimation was conducted to determine the correlation between the accounting determined risk measures (earnings variability, dividend payout, and leverage) and the market determined risk measure (beta). 
The results of the estimation suggest that there is significant relationship between beta and both leverage and dividend payout; however, we obtained differing results for earnings variability. The discrepancy between our results for earnings variability and the BKS (1970) findings is particularly surprising because earnings variability has the highest correlation with beta in the BKS study. Additionally, while the relationship held true for dividend payout with the entire sample, the dividend payout relationship was not robust across the subsamples. The dividend payout relationship did not hold true for firms with a large market capitalization. It is likely that virtually all large companies pay dividends; therefore, dividend payout it is not a good indicator of risk across the large firms. Conversely, there is much more variation in dividend policy of small to medium sized firms.

The results of this study provide support for importance of financial statement in the capital markets and their role of reporting not only a firm's earnings, but also their risk profile. The relationship between accounting and market based risk measures suggest that accountant's role in reporting financial information is important to asset allocation decisions. The results also reiterate the importance of accountant's policy choice and disclosure in the financial statements to the capital markets.

While the results of this study are informative, there are inherent limitations. A main limitation is that our results were obtained at a point in time (cross section), rather than over time periods (time series) as in the BKS (1970) study. Future researchers may be it useful to expand the study to cover longer time periods to see if the relationships holds true. A further course of investigation based on the findings of this study may additionally be to further research the impact of accounting risk measures and market risk measures as accounting policies move from historical cost based to fair value based accounting choices.

The remainder of the paper is organized as follows. First, a literature review is provided to review the important works and theories that preceded this study, leading to the formulation of the research question. Secondly, the sample and methodology used is presented. Finally, the results were presented along with a discussion and concluding remarks.

\subsection{LITERATURE REVIEW}

\subsection{Market Risk}

In their 1970 paper, Beaver Kettler and Scholes intuitively define beta as the extent to which security and market returns move together (BKS, 1970). The magnitude of this number reflects the magnitude of the securities movement, with a beta of one meaning the stock's returns rise and decline at the same rate as the market's returns. The sign of the beta is the direction of the movement. A positive beta means the security's returns are in the same direction as the market's and a negative would suggest an inverse relationship between the firm and the market's returns.

There is most definitely a need for accounting information in the capital markets. One of the main reasons comes from the development of the Capital Asset Pricing Model (Sharpe, 1964). For this model to be effective, it is assumed that all investors participating in the market are rational and risk-averse, and are privileged to all information in the market with instant reaction times. Of course, this situation is not the case and, like most decisions, considerable evaluation of information and formation of estimates is required. Accounting data are the measurements used by investors in assessing information and reacting in a timely fashion (Scott, 2006).

\subsection{Accounting Risk}

Just as the Capital Asset Pricing Model requires significant estimates to hold true, so does accounting data. Traditional risk-measure ratios, like debt to equity, or earnings variability are based on many estimates. As Feltham and Ohlson suggest in their Clean Surplus Theory (1995), there is considerable information not contained in accounting statements that can heavily influence an investor's assessment of risk. Expectations of future abnormal earnings leads to the creation of off-balance sheet goodwill and skew the relevance of accounting ratios. 
With the use of so many estimates in both the Capital Asset Pricing Model and accounting data, there is room for interpretation of the term risk. Based on these estimates, it is important to understand if accountants determine risk (liquidity, leverage, cash flows, dividend payouts etc.) the same as way that the Capital Asset Pricing Model determines risk (through the beta estimation).

\subsection{Market Risk vs. Accounting Risk under Ideal Conditions}

Hamada (1972) was one of the first to prove that, over a sample of 304 firms, about $21 \%$ to $24 \%$ of the observed systematic risk of a firm can be explained by the risk it assumes using debt and preferred stock. This study proved, under ideal conditions, at least some of what accountants determine to be risk is related to the systematic measure of risk, beta (Hamada, 1972). Also under ideal conditions, Lev (1970) proved a modest coefficient of multiple determination, $\mathrm{R}^{2}$, between fixed to variable operating costs and beta in all industries tested (except for oil producers).

While these studies are significant in their results and findings, both are not entirely relevant to real-world application, because the basis for their findings is ideal conditions. Of course, reality does not exist under ideal conditions. If these ideal conditions are assumed to not hold for reality, then it is safe to assume the results of these studies do not necessarily hold under non-ideal conditions.

\subsection{Empirical Evidence of Market Risk vs. Accounting Risk}

Thus far, the most significant study examining the relationship between accounting determined and market determined risk has come from the study of three individuals, Beaver, Kettler and Scholes (1970). Over two consecutive periods of five years, BKS measured the beta, dividend payout, growth, leverage, liquidity, asset size, variability and co-variability of earnings for 307 of the New York Stock Exchange's largest firms. The results of the study would be used to formulate the paper, "The Association Between Market Determined and Accounting Determined Risk Measures".

The results of the study are somewhat expected. While growth, liquidity and co-variability of earnings did not prove statistically significant, dividend payout, leverage and earnings variability did. As expected, there was a correlation between beta and leverage and earnings variability, and a high negative correlation between beta and dividend payout ratio. Of course these results seem to make sense. The higher a firm's leverage (use of debt in its capital structure), the more sensitive its earnings will be to changing economic conditions. Efficient Market Theory suggests investors should be aware of this sensitivity and bid more aggressively when conditions improve or deteriorate. The same rationale applies for earnings variability and inversely for dividend payout (Scott, 2006).

The evidence obtained from the BKS (1970) study supports the notion that accounting-based risk measures are included in the firm's market-based risk measure, and that selecting a firm based on its accounting based risk measure is essentially the same as selecting a firm based on its market based risk measure. The results of studies under ideal conditions, in the very least, are partly carried over to real world application. The findings have useful application in two ways: 1) forecasted accounting data can be used to forecast beta risk of a firm, and 2) accounting data can be used as a substitute to beta when the measure is not available.

Of course, with any study, limitations in the method make the study somewhat less relevant to today's markets. First, even though the sample was adequately large, it only incorporated the 307 largest capital stocks of the New York Stock Exchange (NYSE), and second, the research was conducted 40 years ago, when accounting information may have been a more relied upon source of risk measurement for investors. There is not sufficient evidence that proves the same relationship BKS found, holds true for small-cap stocks. Also, with changes in technology, the increased availability of accounting information to all investors and investors relying more on nonaccounting information including Management Discussion and Analysis, analyst information, etc. 


\subsection{Research Question}

Since the pioneering BKS (1970) study, there have been some confirmatory studies (readers are encouraged to review Gonedes (1973), Bowman (1979), and Ismail and Kim (1989)). However, there has been no such study recently. Because there not been a recent confirmatory study it is important to test whether the relationship revealed Beaver, Kettler, and Scholes holds true for firms in today's markets. Today's capital markets are very different from those of the 1990s and 1980s because of the changes in: (1) capital market regulations; (2) accounting standards regarding measurement, recognition, and disclosure; and (3) technology. This leads to the first research question:

$\mathbf{H}_{1}$ : $\quad$ Is there a relationship between accounting and market based risk measures, as suggested by BKS (1970), in today's capital markets.

Secondly, the study also seeks to determine if the relationship also holds true for all firms regardless of market capitalization. This leads to the second research question:

$\mathbf{H}_{2}$ : Is there a relationship between accounting and market based risk measures, as suggested by BKS (1970), in today's capital markets regardless of a firm's market capitalization (size).

\subsection{METHODOLOGY}

\subsection{Defining the Sample}

The sample was constructed based on 222 firms traded on both the NYSE and the National Association of Security Dealers Automated Quotations (NASDAQ). Stocks were chosen, at random, with the intention for equal weighting for firms with small, medium, and large market capitalization. For large market capitalization firms the sample was selected by combining all of the 30 stocks that comprise the Dow Jones Industrial Index, and 44 stocks from the Russell 2000 Large Cap Index. The stocks with medium and small market capitalization were chosen based on the first 74 respectively in alphabetical order from the Russell 2000 Medium Cap Index, and the Russell 2000 Small Cap Index. To create a random sample, all stocks chosen from the Russell Indexes were chosen in alphabetical order, as there is no known correlation between the letter the company name of a firm begins with and market or accounting performance. Yahoo Finance was chosen as the source of financial data because both the market and accounting risk measures were readily available, reducing the data collection necessary to perform the analysis. Consistency of the source for financial information also ensured the measurements retrieved were calculated uniformly. It is difficult to approximate the bias that may come into play by constructing and choosing the sample in this fashion, but it is believed that this sample is an adequate representation of the population.

\subsection{Determining the Measures}

This study was conducted as a cross-sectional study, where by all measures were taken based on the information available at a single point in time (March 7, 2008). This was done to minimize the effect of other variables that could affect the relationship between the market and accounting risk measures that are to be discussed below.

\section{2(a) Market Risk}

The measure of market risk, chosen to be consistent with the original study, was beta. This can be represented mathematically as: 


\section{Equation 1: Calculating Beta of "A" Shares (Scott, 69)}

$$
\beta_{A}=\frac{\operatorname{Cov}(A, M)}{\operatorname{Var}(M)}
$$

BKS (1970) note that the calculation of beta on different market indices present very little variation as the market indices are highly correlated, eliminating the problems that may occur in the current analysis from drawing stocks from two different indices (Fisher, 1966 and 1967). A comparative was done comparing the average market risk of securities in the BKS study (1970), and the average market risk used in this study. The similar averages suggest the firms studied displayed similar beta measurements as BKS (1970).

\section{Table 1: Current Market Risk Statistics vs. Original Market Risk Statistics}

\begin{tabular}{|c|c|c|c|}
\hline \multicolumn{4}{|c|}{$\begin{array}{c}\text { Market Risk Statistics in Current Study } \\
\text { vs. Market Risk Statistics in Original Study }\end{array}$} \\
\hline & Mean & $\begin{array}{l}\text { Standard } \\
\text { Deviation }\end{array}$ & Range \\
\hline \multirow{4}{*}{$\begin{array}{l}\text { Original Study } \\
\text { Period One } \\
\text { Period Two } \\
\text { Current Study }\end{array}$} & & & \\
\hline & 0.991 & 0.336 & .17 to 2.15 \\
\hline & 0.987 & 0.342 & $(.05)$ to 2.19 \\
\hline & 1.12 & 0.65795 & $(.25)$ to 3.76 \\
\hline
\end{tabular}

\section{2(b) Accounting Risk}

Three of the accounting risk measures utilized in the original BKS (1970) study were chosen based on the findings of the original study, and the relevance to current accounting theory. These measures were dividend payout, leverage, and earnings variability.

Dividend payout was measured based the dividend payout ratio of the firm at the point in time of the study. The dividend payout ratio can be defined mathematically as:

\section{Equation 2: Dividend Payout Ratio (BKS, 1970)}

DividendPayout $=\frac{\sum \text { Cash Dividends Paid to Common Shareholders }}{\sum \text { Income Avaliable to Common Shareholders }}$

Leverage was determined by the debt to equity ratio of the firm. This is a slight variant on the original study, which utilizes the debt to total assets ratio as the measure of leverage. Using debt to equity as an alternative is not expected to provide markedly different results, and was chosen based on the availability of the information.

The debt to equity ratio is calculated as:

\section{Equation 3: Debt to Equity Ratio}

$$
\text { Debt to Equity }=\frac{\text { Debt }}{\text { Equity }}
$$

The third measure, earnings variability was determined based on the standard deviation of the firm's price to earnings ratio over a five year period. This was found by first determining the P/E ratio. Next, the standard deviation was calculated based on the following identity: 


\section{Equation 4: Formula for Standard Deviation}

$$
\sigma=\sqrt{\frac{1}{N}} \sum_{I=1}^{N}\left(x_{i}-\bar{x}\right)^{2}
$$

Finally, a linear regression was run between the market-determined risk measures and the accountingdetermined risk measures.

\subsection{RESULTS}

The results obtained from the OLS regression estimation, as well as the results found in the BKS (1970) study are presented below. Table 2 reveals that there exists a relationship between the accounting and market based risk measures. Furthermore, the p-values are significant in each case, except for the dividend payout ratio for large cap stocks, which is as expected.

Table 2: Current Findings vs. BKS (1970) Findings

\begin{tabular}{|c|c|c|c|c|c|}
\hline & $\begin{array}{c}\text { BKS } \\
1947-56 \\
\end{array}$ & $\begin{array}{c}\text { BKS } \\
1957-65 \\
\end{array}$ & $\begin{array}{l}\text { All } 222 \\
\text { Stocks }\end{array}$ & $\begin{array}{l}\text { Large Cap } \\
\text { Stocks }\end{array}$ & $\begin{array}{c}\text { Midcap \& Small } \\
\text { Cap Stocks }\end{array}$ \\
\hline Dividend Payout & -0.49 & -0.29 & $\begin{array}{l}-0.46 \\
(* * *) \\
\end{array}$ & $\begin{array}{c}0.05 \\
(0.79) \\
\end{array}$ & $\begin{array}{c}-0.45 \\
(* *) \\
\end{array}$ \\
\hline Leverage & 0.23 & 0.22 & $\begin{array}{c}0.10 \\
(0.04) \\
\end{array}$ & $\begin{array}{c}0.20 \\
(0.08) \\
\end{array}$ & $\begin{array}{c}0.09 \\
(0.10) \\
\end{array}$ \\
\hline Earnings Variability & 0.66 & 0.45 & $\begin{array}{c}0.04 \\
(* * *)\end{array}$ & $\begin{array}{c}0.07 \\
(* * *)\end{array}$ & $\begin{array}{c}0.04 \\
(* * *)\end{array}$ \\
\hline
\end{tabular}

Table 3: Correlation of Measures and Sample Stocks

\begin{tabular}{|c|c|c|}
\hline Sample & Measures & Correlation \\
\hline All 222 Stocks & Beta and Dividend Payout & -0.24 \\
\hline All 222 Stocks & Beta and Leverage & 0.16 \\
\hline All 222 Stocks & Beta and Earnings Variability & 0.39 \\
\hline Large Cap Stocks & Beta and Dividend Payout & 0.03 \\
\hline Large Cap Stocks & Beta and Leverage & 0.24 \\
\hline Large Cap Stocks & Beta and Earnings Variability & 0.50 \\
\hline Midcap \& Small Cap Stocks & Beta and Dividend Payout & -0.26 \\
\hline Midcap \& Small Cap Stocks & Beta and Leverage & 0.16 \\
\hline Midcap \& Small Cap Stocks & Beta and Earnings Variability & 0.38 \\
\hline
\end{tabular}

The following is a discussion and analysis of the results.

\subsection{Dividend Payout}

The relationship between the dividend payout ratio and the beta of a firm was quite strong. The results showed a correlation of -0.46 between the two, suggesting that beta does in fact decrease as the dividend payout ratio increases. One would expect this as firms not having funds available to be paid out in dividends are typically more risky and hence, would have a higher beta. The BKS (1970) study produced similar results, as the correlation was -0.49 and -0.29 in the two periods. The fact that the relationship has held constant over time leads us to believe 
that the amount of dividends a firm pays is an important determinant of its beta. However, when the results were further broken down between large cap stocks, midcap stocks, and small cap stocks, a rather interesting relationship appeared.

When analyzing the relation between beta and dividend payout for large cap stocks alone, the results were rather intriguing and surprising. There was little relation between the two and the correlation (coefficient of 0.05) and the sign was positive as opposed to the expected negative. This is a very weak relationship, but it suggests that beta increases as the dividend payout ratio increases for large cap stocks, which is the opposite of what one would expect. The relationship between beta and dividend payout ratio for the midcap and small cap stocks was what one would expect, as the correlation was -0.45 .

A possible explanation for the lack of a relationship between the two measures for large cap stocks lies within the analysis of how many of the firms in each category actually paid dividends. 89\% (66 of 74) of the large cap stocks chosen for the study paid dividends, while 66\% (49 of 74) of the midcap stocks and only $41 \%$ (30 of 74) small cap stocks paid dividends. This leads to a couple of issues when the results are broken down to separate the large cap stocks from the midcap and small caps. With such a high percentage of the large cap stocks paying dividends, it becomes increasingly difficult for an association to be present within the data.

A second point to consider is the fact that the large cap stocks are companies that are quite strong financially and have the ability to pay out a wide range of amounts in the form of dividends should they choose to do so. The smaller firms, in general, have less cash on hand to pay out to shareholders and thus the payout ratios that they will have are within a relatively fixed range. This will allow for a relationship to be present as the dividend payout ratios will be fairly similar for the smaller firms as they are not financially capable of paying out very large amounts for the most part. On the other hand, the large firms are financially sound and two of them in identical positions, with similar betas, may choose to take a different approach when paying dividends. For example, they may historically have had different dividend policies, leading one to pay out $20 \%$, while the other pays $60 \%$. The firm that chose to retain $80 \%$ and pay out the smaller amount in dividends is doing so by choice and not because they are not capable of paying a larger amount. Situations like this will lead to more random results among the large cap stocks and will lead to a weakened relationship, if any, between the two variables. Overall the relationship for all the stocks is what we would expect it to be, but the situations unique to large cap stocks create for unexpected results when the data is broken down by market capitalization.

\subsection{Leverage}

As was expected, the results for leverage indicated that as leverage increases, beta increases as well. The correlation between leverage and beta was 0.10 for our study, compared to 0.23 and 0.22 for the BKS (1970) study. This shows that the relation has weakened slightly over time, but as noted in the BKS (1970) study, a correlation of 0.10 or greater is considered to be significant.

The results were again further broken down to see if the relationship held true for large cap stocks and for the combination of midcap and small cap stocks. The results for the large cap stocks was as expected, with a correlation of 0.20, an immaterial difference from what was discovered in the BKS (1970) study years ago. The midcap and small cap stocks produced a correlation of 0.09 when their betas and leverage were compared. This is just shy of the 0.10 value that is considered "significant," illustrating that the relation between beta and leverage is weaker for smaller firms, but however is still fairly significant.

The overall results indicate that the relationship between beta and leverage holds true to that which was calculated in the BKS (1970). The relation for large cap stocks is nearly identical to that of the BKS (1970) study, which is important, as large cap stocks were the focus of their study, indicating that things have remained constant since the publishing of their study. 


\subsection{Earnings Variability}

Earnings variability showed the weakest relationship of the three variables tested. The correlation between earnings variability and beta was 0.04 , indicating a weak positive relationship. The BKS (1970) study showed quite different results, as this was the strongest of their relations, with correlations of 0.66 and 0.45 .

The large cap stocks provided us with a correlation of 0.07 , slightly above the aggregate of all the stocks used in the study, but still well below that of the BKS (1970) study. The combination of midcap and small cap stocks showed a slightly weaker relation that both the large cap stocks alone and the aggregate of all stocks, with a correlation of 0.04 .

A potential reason for such a weak relation compared to the BKS (1970) study is the fact that we have experienced bubbles in recent years that have distorted P/E ratios as they soared to high levels. Additionally, the measure used for earnings variability may not be the best in today's market and may also have had an effect on the results. These could help explain why there is little to no relation between beta and earnings variability in our study.

\subsection{CONCLUSION}

Our results corroborate the original BKS (1970) findings that there is a correlation between market risk and accounting risk measures (to the extent explored in this study). However, the magnitude of the correlation is not as strong as noted in the BKS (1970) study. Furthermore, the sign of the correlation coefficient is the same as the BKS (1970) study.

The results of this study corroborate the significance of accountants and financial statement in the role of reporting risk. It is shown that there is a relationship between accounting risk, and market risk measures, meaning the accountant's role in reporting information becomes more important than ever. In the absence of beta (i.e. for firms without previous market returns, or forecasted returns), accounting information can be used to assess company-specific risk. The places great emphasis on the accountant to provide information that is both relevant and reliable.

Each measure in this study: earnings variability, leverage and dividend payout is based upon the accountant's interpretation of the underlying measurements used to calculate the measure. It is very important then for accountants to present their interpretation on information that is both relevant and reliable. Of course, perfect reliability and relevance is impossible to achieve, and the accountant faces a trade-off.

It appears the results support the notion that there is information content in fair values that accountants incorporate into financial statements through the measurement perspective (Scott, 2006). The use of the measurement perspective would suggest all balance-sheet items be recorded at fair value to be entirely relevant to decision makers. This would ensure there are no off-balance sheet items that investors could use to evaluate risk. If all debt, for example, were recorded at fair value, the leverage ratio would be more relevant. This relationship also holds true for dividend payout ratio and earnings variability. It appears a transition to more fair-value based accounting will provide for an even stronger relationship between beta and accounting risk, as the increased relevance of the measurement perspective will be more useful to investors in assessing firm-specific risk.

This study and its findings reinforce the importance of accounting information to investors, and prove it to be an alternative to market risk information. This finding reiterates the importance of accountant's policy choice and disclosure in the financial statements to the capital markets, and demonstrates how important the relevance vs. reliability trade-off is when determining accounting treatment.

As this study was limited to a point in time, and a sample of 222 firms, there are inherent limitations to the usefulness of the results. Using this study as a basis, it would be worthwhile to expand the sample over a longer time period to study the changes that may occur as we transition from historical cost based to fair value based accounting disclosures. 


\section{ACKNOWLEDGEMENTS}

We would like to thank Professor Camillo Lento for providing us with the knowledge, support, and guidance to complete this study.

\section{AUTHOR INFORMATION}

Michael Jarvela is a fourth year commerce student, majoring in accounting. Upon completion of his undergraduate degree, Michael wishes to continue his education with a Masters of Business Administration. Michael is currently pursuing a Chartered Accountant designation and wishes to eventually become a partner in his firm.

James Kozyra is a graduate student at Lakehead University in the Masters of Science in Management program. He achieved his undergraduate education at Lakehead University in the Honours Bachelor of Commerce program with a double major in finance and accounting. His research interests are in the area of capital markets.

Carla Potter is a graduate of the Honours Bachelor of Commerce program at Lakehead University. She is currently employed at Grant Thornton LLP while pursuing a CA designation.

\section{REFERENCES}

1. Beaver, W.H., P. Kettler, and M. Scholes, The Association Between Market-Determined and AccountingDetermined Risk Measures, The Accounting Review, October 1970

2. Bowman, R.G. (1979), The Theoretical Relationship Between Systematic Risk and Financial. Accounting Variables, Journal of Finance, 34(3), pp. 617-630

3. Feltham, G.A. and J.A. Ohlson, Valuation and Clean Surplus Accounting for Operational and Financial Activities, Contemporary Accounting Research, Spring 1995

4. $\quad$ Fisher, L., Some New Stock Market Indexes, Journal of Business, 1966

5. Fisher, L., M. Jensen, and R. Roll, The Adjustment of Stock Prices to New Information, Center for Mathematical Studies in Business and Economics, University of Chicago 1967

6. Gonedes, N J (1973), Properties of accounting numbers: models and tests. Journal of Accounting Research Autumn, 212-237.

7. Hamada, R., The Effect of the Firm's Capital Structure on the Systematic Risk of Common Stocks, Journal of Finance, May 1972

8. Ismail, B.E. and Kim, M.K. (1989), On the association of cash flow variables with market risk: further evidence, Accounting Review, Vol.64, pp 125-36

9. Lev, B., On the Association Between Operating Leverage and Risk, Journal of Accounting Research, 1989

10. Scott, W., Financial Accounting Theory, $4^{\text {th }}$ Edition, Pearson Education Canada Inc., 2006, 2003, 2000, 1997.

11. Sharpe, W. F. (1964)., Capital asset prices: A theory of market equilibrium under conditions of risk, Journal of Finance, 19 (3), 425-442 


\section{NOTES}

